Калашникова И.В. ${ }^{1}$, Мироненко О.В. ${ }^{2}$

${ }^{1}$ Тихоокеанский государственный университет, г. Хабаровск

2 Дальневосточный государственный университет путей сообщения, 2. Хабаровск

\title{
Трансферты домашних хозяйств: сущность, типология, факторы их формирования
}

\begin{abstract}
АННОТАЦИЯ
Домашние хозяйства играют важную роль в экономике государств, поскольку родственные связи имеют большую стабильность, чем организационные. В современных исследованиях основное внимание уделяется доходам и расходам, выраженным в денежной форме, но межпоколенные трансферты, формирующие значительную часть капитала домашних хозяйств, остаются малоизученными.

Для изучения межпоколенных трансфертов авторы адаптировали применительно к домашним хозяйствам экономические модели «жизненного цикла» Ф. Модильяни и «перманентного дохода» М. Фридмана, а также «мотивационные» модели альтруизма, обмена, теории социальных сетей и реципрокности, широко используемые социологами. Результатом исследования стала типология трансфертов, возникающих между домашними хозяйствами, выраженная в форме матрицы, что поможет в дальнейшем разработать более взвешенную политику доходов на федеральном и региональных уровнях, а также в деятельности Министерства труда и социальной защиты.
\end{abstract}

КЛЮЧЕВЫЕ СЛОВА: домашние хозяйства, межпоколенные трансферты, доходы домохозяйств

JEL: E20, D19, D31, J40

ДЛЯ ЦИТИРОВАНИЯ:

Калашникова И.В., Мироненко О.В. Трансферты домашних хозяйств: сущность, типология, факторы их формирования // Экономика труда. - 2014. - № 1 (1). - С. 59-68. http://www.creativeconomy.ru/journals/index.php/et/article/view/11/

Калашникова Ирина Владимировна, заведующая кафедрой «Производственный менеджмент» Тихоокеанского государственного университета, доктор экономических наук, профессор

Мироненко Ольга Владимировна, доцент кафедры «Экономика», кандидат экономических наук, (mirono1983@mail.ru)

ПОСТУПИЛО В РЕДАКЦИЮ: 17.10.2014 / ОПУБЛИКОВАНО: 28.12.2014

ОткрытыЙ дОстУп:

http://www.creativeconomy.ru/journals/index.php/et/article/view/11/

(c) Авторы / Публикация: ООО Издательство "Креативная экономика"

Статья распространяется по лицензии Creative Commons CC BY-NC-ND

(http://creativecommons.org/licenses/by-nc-nd/3.0/)

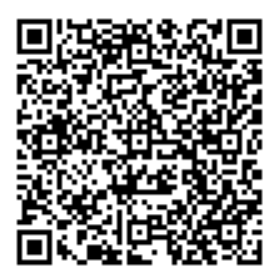

ЯЗЫК ПУБЛИКАЦИИ: русский

Metadata in English is available at

http://en.creativeconomy.ru/journals/index.php/et/article/view/11/ 
Для некоторых домашних хозяйств трансферт как форма сетевых взаимодействий является единственным источником существования, позволяющим выживать в критических ситуациях. С этой точки зрения указанные трансфертные потоки можно интерпретировать как нерыночный механизм перераспределения доходов и собственности, а трансферт - как инструмент нивелирования, сглаживания расслоения общества и выравнивания уровня жизни. Поэтому исследования такого рода «представляют особый интерес для государственных и негосударственных организаций, отвечающих за социальную помощь разным группам населения» [4].

Цель данного исследования заключалась в том, чтобы проанализировать существующие подходы к понятию «межпоколенные трансферты» в экономической и социальной науках, получить их классификацию для дальнейшего использования в деятельности Министерства труда и социальной защиты.

Отметим, что некоторые исследователи получателя трансферта определяют в качестве акцептора [3; 6]. Несмотря на то, что указанное понятие в переводе с латинского (ассіріо) означает «я принимаю, получаю» и обозначает объект, принимающий что-либо от донора, оно используется во многих отраслях научного знания: химия, молекулярная биология, сфера поисковой оптимизации, психология, медицина и др. В зависимости от области исследований термин «акцептор» имеет разное содержание: группа атомов, принимающих электроны и образующих химическую связь; вещество, принимающее электроны и водород от окисляемых соединений; сайт, на который ссылаются другие сайты; сеть вставочных нейронов, являющаяся моделью будущих результатов действия и др. Именно поэтому в своих работах мы предпочитаем оперировать термином «реципиент», который давно «закрепился» и в экономике, и в социологии.

Отметим, что, несмотря на относительно высокую вовлечённость населения в сферу трудовой занятости, немаловажное значение для обеспечения качества жизни населения имеют трансферты, опосредующие взаимодействие и взаимосвязи между домашними хозяйствами. В данном контексте трансферт следует трактовать как безвозмездную помощь, оказываемую членами одного домашнего хозяйства (донором) другому (реципиенту). 
В структуре трансфертов между домашними хозяйствами основными являются межпоколенные, среди которых особое место занимают межсемейные трансферты, выделяемые Е.В. Гладниковой, Н.Н. Нестеровой, а также родственные трансферты [2, 3]. Каждый из упомянутых видов трансфертов может быть «нисходящим» (предоставление помощи представителями старшего поколения младшему) или «восходящим» (помощь представителей младшего поколения старшему).

Межпоколенные трансферты исследуются в экономике, социологии, демографии, психологии. Очевидно, что предмет исследования трансфертов в каждой из указанных областей наук различен. Это могут быть мотивы оказания помощи, социальные предпосылки обмена ресурсами, взаимопомощь как психологический аспект отношений и т.д. Мы же остановимся на трансфертах, изучаемых с позиции теоретической экономики и социологии.

В экономической плоскости при изучении межпоколенных трансфертов особый интерес представляют их цель и направления. Для этого нами были адаптированы применительно к домашним хозяйствам модели «жизненного цикла» $\Phi$. Модильяни и «перманентного дохода» М. Фридмана. Обе модели основаны на теории, согласно которой потребление в каждом периоде зависит от дохода, ожидаемого в течение всей жизни, а не от дохода в текущем периоде.

Модель «жизненного цикла» основывается на утверждении, что потребление зависит от величины дохода за период, равный длине жизненного цикла индивидуума или семьи. Поэтому стратегия потребления формируется индивидом с учетом сохранения уровня потребления в период трудовой занятости на этапе пенсионного периода жизненного цикла. Согласно же модели М. Фридмана, потребление индивида пропорционально уровню перманентных доходов, равных средней величине доходов за период, длительность которого превышает один год. Таким образом, с позиции рационального поведения индивида каждый стремится к сбережениям в трудовой период с тем, чтобы сохранить уровень потребления в период отсутствия стабильного трудового дохода. Это фактор, влияющий на величину трансфертов домашних хозяйств.

Интерпретируя рассмотренные модели применительно к домашним хозяйствам, можно утверждать, что соотношение потребления и сбережений в домашнем хозяйстве зависит от этапа его 
жизненного цикла и от величины соответствующих аккумулируемых доходов. Однако, говоря о трансфертах домашних хозяйств, в российских условиях нельзя игнорировать текущие доходы их членов (по причине недоверия населения к государственным программам социального обеспечения, социальной поддержки и социальной защиты).

Вернемся к теории «жизненного цикла», согласно которой совокупный доход среднестатистического домохозяйства имеет тенденцию к сокращению, в лучшем случае к сохранению. Поэтому стратегия трансфертов будет определяться текущей стадией жизненного цикла: трудовой период членов домашнего хозяйства (ЧДХ) сопряжен с активизацией «нисходящих» трансфертов, пенсионный - «восходящих».

Решение о передаче ресурсов, вид трансферта домашнего хозяйства в модели мотивов, широко используемой социологами и психологами, зависят от соотношения доходов домохозяйства-донора и доходов реципиента. В «мотивационной» концепции альтруизма предполагается, что аргументом функции полезности для донора является желание безвозмездно помогать нуждающимся ввиду потребности быть нужным. Чтобы максимизировать полезность донор стремится к равновесию между «передачей» части получаемого дохода (трансфертом) и потреблением. Таким образом, концепция альтруизма основана на ординалистской теории потребления, где в качестве одного товара (благо) выступает желание помочь, а другого - сохранение уровня личного потребления. Очевидно, что графически оптимум для домохозяйства-донора - это точка касания кривой безразличия и бюджетной линии (рисунок 1). 


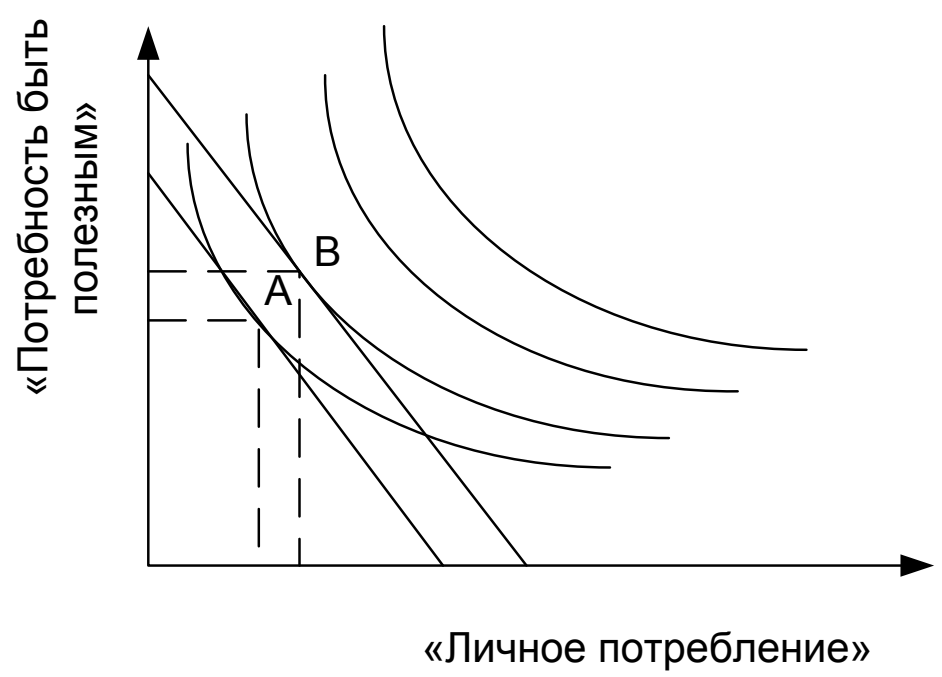

Рисунок 1. Кривая безразличия и бюджетная линия конкретного домашнего хозяйства (источник - составлен авторами)

Точки равновесия А и В и их разное положение объясняется разной мотивацией трансфертного поведения конкретного домашнего хозяйства в разные периоды жизненного цикла. Так, в точке касания А первостепенное значение для домохозяйства имеет потребность в оказании помощи (желание помочь), в точке В преобладает потребность в сохранении уровня личного потребления

Ещё одна важная идея «мотивационной» концепции обмена состоит в том, что члены домашних хозяйств осуществляют различные виды трансфертов, полагая, что в долгосрочной перспективе будут вправе рассчитывать на помощь (обратная связь).

Для изучения межпоколенных трансфертов в рамках социальных наук применяются теории социальных сетей и реципрокности. Начало сетевому анализу было положено Х. Уайтом и М. Грановеттером (на примере рынка труда). Сегодня в сетевом подходе есть несколько подходов, которые объединяются трактовкой сети как основного структурного элемента мира.

На теории сетей выстроены многие исследования Г.В. Градосельской. В ее интерпретации социальные сети представляют собой совокупность связей, по которым передаются различного рода ресурсы [4]. Зная структуру сети и тип актора (донор, реципиент, обмен, независимый), можно построить сеть графов трансфертов домашних хозяйств. 
Реципрокность (от лат. reciprocus, «взаимный») является одним из способов передачи благ на внерыночной основе [7]. Это один из возможных типов отношений в сетевой структуре. В основе других отношений, как правило, лежат прагматичные мотивы максимизации доходов, минимизации расходов и др. Поскольку сущностью домашнего хозяйства является «производство ради потребления», то оно основывается на концентрации «ресурсов в едином центре с последующим распределением по неким критериям, принятым в данном сообществе» [1]. Следовательно, реципрокность в экономике домашних хозяйств - это взаимообмен, альтернативный вариант (рынку и государственному бюджетному перераспределению) трансферта благ между домохозяйствами. Фактически реципрокность является социальным амортизатором в условиях, когда иные механизмы социальной поддержки фактически не работают. В таком контексте уместна идея Маршалла Салинса, различающего три типа реципрокности: генерализованную (когда отдают, не требуя возмещения), сбалансированную (когда принято впоследствии возмещать) и негативную (когда преследуются корыстные цели извлечь больше выгоды в будущем, нежели понесенные издержки в настоящее время) [8].

Наше понимание реципрокности коррелирует с концепцией С.Ю. Барсуковой, которая трактует реципрокность как «нерыночные обмены между домохозяйствами», отличающиеся от патрон-клиентских и товарообменных отношений [1].

С учетом вышеупомянутых моделей межпоколенные трансферты мы подразделяем на денежные, материальные, социально-трудовые, социально-культурные и интеллектуальные.

Денежные трансферты предполагают безвозмездную передачу одним домашним хозяйствам другому денежных средств, ценных бумаг, владелец которых обладает правом получения дохода. Под материальными трансфертами будем понимать совокупность потребительных стоимостей в вещественной форме (имущество, товары, предметы личного потребления), передаваемых одним домашним хозяйством другому. Социально-трудовые трансферты представляют собой помощь в ведении хозяйства, на приусадебном участке, выполнении домашних работ, по уходу за детьми, больными, инвалидами. Социально-культурные трансферты реализуются через особенности социального взаимодействия, социальную структуру 
общества, социальный капитал, услуги здравоохранения, вкусы, предпочтения, образование, культуру и искусство. Интеллектуальные трансферты связаны со способностями и свойствами человека как активного участника воспроизводственного процесса, такими как здоровье, организационно-предпринимательские и культурнонравственные возможности домохозяйства.

В рамках изучения трансфертов, возникающих между домашними хозяйствами, используя матрицу, составленную по критерию «тип трансферта - направление трансферта», можно выделить несколько типов трансфертных потоков (стратегий трансфертного поведения домашнего хозяйства) (рисунок 2).

\begin{tabular}{|c|c|c|c|c|c|c|}
\hline & \multicolumn{5}{|c|}{ тип трансфертов } \\
\hline & & денежные & материальные & $\begin{array}{c}\text { социально- } \\
\text { трудовые } \\
\end{array}$ & $\begin{array}{l}\text { социально- } \\
\text { культурные }\end{array}$ & интеллектуальные \\
\hline 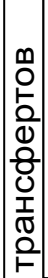 & 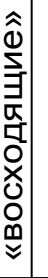 & $\begin{array}{c}\text { денежные } \\
\text { «восходящие» }\end{array}$ & $\begin{array}{l}\text { материальные } \\
\text { «восходящие» }\end{array}$ & $\begin{array}{c}\text { социально- } \\
\text { трудовые } \\
\text { «восходящие» }\end{array}$ & $\begin{array}{c}\text { социально- } \\
\text { культурные } \\
\text { «восходящие» }\end{array}$ & $\begin{array}{c}\text { интеллектуальные } \\
\text { «восходящие» }\end{array}$ \\
\hline 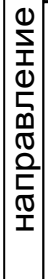 & 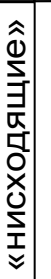 & $\begin{array}{c}\text { денежные } \\
\text { «нисходящие» }\end{array}$ & $\begin{array}{l}\text { материальные } \\
\text { «нисходящие» }\end{array}$ & $\begin{array}{c}\text { социально- } \\
\text { трудовые } \\
\text { «нисходящие» }\end{array}$ & $\begin{array}{c}\text { социально- } \\
\text { культурные } \\
\text { «нисходящие» }\end{array}$ & $\begin{array}{c}\text { интеллектуальные } \\
\text { «нисходящие» }\end{array}$ \\
\hline
\end{tabular}

Рисунок 2. Матрица распределения стратегий трансфертного поведения (источник - составлен авторами)

В ходе проведенного нами в январе 2014 г. анкетирования членов 100 домашних хозяйств Хабаровского и Приморского краев установлено, что в указанных регионах наибольшее распространение имеет практика нисходящего трансфертного донорства, основной из причин которого является старение населения.

\section{Результаты}

Очевидны проявления различий в содержании нисходящих и восходящих трансфертов: если для первых характерна всесторонняя помощь, то для вторых - в большей степени социально-трудовая. 
Причем нисходящая материальная и нисходящая социально-трудовая поддержка может оказываться разным представителям младшего поколения, поскольку получение каждых из этих ресурсов выделилось как две отдельные стратегии.

На формирование трансфертов домашних хозяйств оказывает влияние совокупность факторов. Наиболее значимыми, на наш взгляд, являются следующие:

- социально-демографические процессы;

- экономическая активность на территории проживания;

- занятость участников трансфертного обмена;

- образование;

- семейное положение;

- совокупный доход домашнего хозяйства;

- стадия жизненного цикла участников трансфертного обмена;

- поддержка родственных связей.

Следует отметить, что в статье представлены основные факторы формирования трансфертных потоков между домашними хозяйствами, оказывающие наибольшее влияние на вектор и объем трансфертов.

Практическая значимость исследования заключается в использовании, предложенной типологии межпоколенных трансфертов, в разработке более взвешенной политики доходов на федеральном и региональных уровнях, а также в деятельности Министерства труда и социальной защиты.

ИСТОЧНИКИ

1. Афанасьев К.И. Сберегательно-инвестиционные направления, доступные для пользования домашними хозяйствами (на примере Республики Татарстан) // Региональная экономика: теория и практика, 2012. - № 11. С. 22-25.

2. Барсукова С.Ю. Реципрокные взаимодействия. Сущность, функции, специфика [Электронный ресурс]. - Дата обращения 10.08.2014.

3. Гладникова Е.В. Межпоколенные трансферты: направление, участники и факторы, их определяющие // Экспертное мнение, 2007. - № 7. С. 125-148.

4. Гладникова Е.В. Ключевые стратегии участия и типология российских домохозяйств в межсемейных обменах: Препринт WP4/2009/05. - М.: Изд. дом Государственного университета - Высшей школы экономики, 2009. - 60 с.

5. Глухов В.В. Сбережения домашних хозяйств как источник инвестиций // Азиатскотихоокеанский регион: Экономика, политика, право, 2008.- № 2. С. 55-58.

6. Глухов В.В. Специфика финансов домашних хозяйств // Финансовые исследования, 2007. - № 17. C. 83-86. 
7. Градосельская Г.В. Социальные сети: обмен частными трансфертами // Социологический журнал, 1999. - № 1/2. С. 156-163.

8. Земцов А.А., Осипова Т.Ю. Кредитный скоринг косвенный метод оценки богатства домашних хозяйств // Вестник Томского государственного университета. Экономика, 2008. - № 2. С. 17-38.

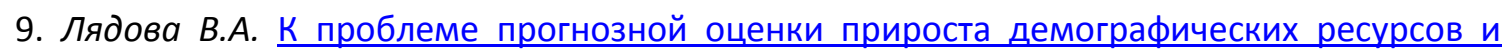
эффективности их трансформации в используемые трудовые ресурсы // Российское предпринимательство, 2012. - № 3 (201). - С. 60-64.

10. Малинова Т.П. Формирование домашних хозяйств и особенности их поведения в переходной экономике // Вестник Красноярского государственного педагогического университета им. В.П. Астафьева. 2006. - № 3. С. 239-250.

11. Москвина Н.В. Основные направления развития форм занятости в сельских домашних хозяйствах в Республике Бурятия // Известия Иркутской государственной экономической академии, 2007. - № 2. С. 79-81.

12. Нестерова Н.Н. Межпоколенный трансферт в развитии региональной экономики // Вестник ОрелГИЭТ, 2013.- №2. С. 54-58.

13. Неформальная экономика в российских домохозяйствах в первой половине 2000-х: домашний труд, агропроизводство и межсемейные трансферты [Текст] /E. Гладникова, М. Нагерняк, Я. Рощина, А. Сухова; отв. ред. сер. В.В. Радаев; Нац. исслед. ун-т «Высшая школа экономики», Лаб. экон.-социол. исслед. - М.: Изд. дом Высшей школы экономики, 2013. - 220 с.

14. Осипова Т.Ю. Система финансового планирования в домашних хозяйствах // Вестник Томского государственного университета. 2012. № 359. С. 135-138.

15. Поланьи К. Экономика как институционально оформленный процесс // Экономическая социология Т.3. №2. 2002 [Электронный ресурс]. - Дата обращения 09.07.2014.

16. Попов М.В. Домашнее хозяйство в современной институциональной среде // Известия Волгоградского государственного технического университета. 2012. -№ 16 (103). С. 91-95.

17. Рогачева О.A. Стоимостная оценка богатства, накопленного в домашних хозяйствах населения Иркутской области // Известия Иркутской государственной экономической академии, 2011. - № 1. С. 126-130.

18. Салинз М. Экономика каменного века. - М.: ОГИ, 1999. - 296 с. 
